Troubles with I.U.C.D.s

SIR,-I refer to Dr. Ursula E. Mountrose's letter (2 June, p. 551) in which she describes her clinical impression that preliminary immersion of the plastic package containing the Dalkon Shield in hand-hot water for five minutes facilitates the insertion procedure.

Regrettably, this is not a new suggestion, and in fact there are a few contraceptive clinics carrying out this preliminary procedure at the present time. Nevertheless, we have not seen fit to include this as part of our normal insertion procedure because we have not found sufficient people experiencing difficulty in inserting the Dalkon Shield without this preliminary warming. I am often asked if it is not more difficult to insert the Dalkon Shield than other intrauterine devices. I usually counter this question by saying that the correct word to use is not "difficult" but "different" in that one has to push the folded device through the cervix against counter traction provided by a tenaculum applied to the cervix, rather than by the use of a soda straw type of inserter, and in any event the very low expulsion rates of the Dalkon Shield would seem to compensate adequately for this refinement in insertion technique.

We have found that the great majority of physicans who have thoroughly familiarized themselves with the insertion procedure for the Dalkon Shield do not find it "difficult" and hence do not require to warm the device prior to insertion.-I am etc.,

J. S. TempletoN

Horsham, Sussex A. H. Robins Co.

\section{The Problem Oriented Medical Record}

SIR,-Dr. Neil McIntyre (9 June, p. 598) has given us an excellent résumé of the philosophy behind the problem oriented medical record as described by Professor L. L. Weed. He clearly summarizes the most important areas of benefit accruing from the use of such records in medical practice. As a general practitioner with experience in the use of this type of record, I would like to complemen his remarks with what I consider to be important practical benefits in practice outside the hospital.

The problem oriented record is ideally suited to general practice use. The provision of a problem list index to each patient's record can speed access to important information, obviate the possibility of overlooking important coincident problems, and enable colleagues to discuss clinical problems in context. Dr. McIntyre did not mention the use of flow charts. These are a valuable adjunct to the progress notes. In my experience confused management of complex problems can be detected and dealt with more readily once a flow chart has been constructed. Common applications include the management of chronic diseases such as hypertension, diabetes, and comolex emotional disorders, as well as child development and obstetrics. Many doctors are already familiar with the use of flow charts in this latter context.

There is considerable benefit to be derived from general practitioners and consultants communicating on a "problem oriented" basis. One frequently encounters patients who have problems for which no one has aocepted responsibility. There may well be excellent care provided by a number of consultants and the family practitioner but, because of a lack of context, the patient fails to gain the full benefit of our diagnostic and therapeutic efforts. Conversely, considerable sincere effort is wasted by lack of coordination. I believe the problem oriented medical record is a valuable tool that can be used to minimize this waste.-I am, etc.,

P. D. HERTNON

University Department of Community Medicine, Southampton General Hospital, Southampton

1 Bjorn, J. C., and Cross, H. D., Problem Oriented Boyle, C. M Alexander, w . D Stevenson, J. G. Bancet, 1973, 1, 249 and 928.

\section{Redesign of Medical Records} in General Practice

SIR,-Having read ECN946 and the recent correspondence in your columns (26 May, $p$. 483; 9 June, p. 613) regarding the introduction of the A4 filing system in general practice, I should like to make some points.

I am a member of a practice whose list is approximately 15,000 and who have recently begun to operate the A4 system and are at present $75 \%$ converted to that system. The storage space suggested at $20 \mathrm{ft}^{2}\left(1.9 \mathrm{~m}^{2}\right)$ per 1,000 records is, in our case, accurate. However, our particular form of A4 folder, and there are many of these, files at approximately 40 per linear foot $(30 \mathrm{~cm})$. There are folders at prerent, I believe, under consideration by the Department of Health and Social Security whose filing density is less than this and if such a document is chosen I feel that this figure of $20 \mathrm{ft}^{2}$ per 1,000 records should be revised. These documents in practice handle very easily and are not inconvenient to have on one's desk or in one's car. They offer considerable advantages to the G.P. since it is possible to display and record data in a form which makes reference a pleasure.

I understand the anxiety expressed in your columns regarding the expense involved. Needless to say the Department has not offered any financial assistance to those practices who have chosen to innovate and anticipate the introduction of this new system, which will have a profound effect on the practice of family medicine.

I should also like to make a plea for the uniform punching of all correspondence which is sent to G.P.s and requires filing, as this would considerably reduce the work load of the records staff and would naturally be reflected in the wage bill which we and the executive councils are required to pay.

All five partners are very impressed with the efficiency of this system and hope that the D.H.S.S. will rapidly introduce an A4 document which has as one of its qualities a high filing density.-I am, etc.,

Corby, Northants

T. BROOKS DONNELLY

\section{Is Your Pain Really Necessary?}

SIR,-I was interested to read Miss Dorothea M. Kerslake's letter (9 June, p. 614) describing the treatment of spasmodic dys- menorrhoea with Cyclandelate. For several years now I have successfully treated most cases of dysmenorrhoea with indomethacin usually in a dose of $25 \mathrm{mg}$ four times a day. It would be interesting to see whether my findings are confirmed by a double-blind trial.-I am, etc.

Hemel Hempstead, Herts

G. G. HILI

\section{Pruritus Vulvae}

SIR,-Running clinics for cervical cytology and family planning, where I see many women suffering from pruritus vulvae and often quite severe inflammatory changes, I can support Mr. C. N. McFarlane (2 June, p. 553) in his view that these conditions are often caused by tights - but also by nylon briefs, pantie girdles, and close-fitting slacks of man-made fibres. In cold weather women often wear these four garments at the same time. When these are replaced by cotton underwear and stockings the condition clears up.

I have had good co-operation from my patients and now have ample proof. I have not found that sensible women, whatever their age, prefer to put up with these unpleasant symptoms rather than give up tights, as Dr. Sally E. Ford (16 June, p. 665) states. -I am, etc.,

Poole, Dorset

ROSA STRUNIN

\section{Appointment of Preregistration House} Officers

SIR,-I was interested to read the article by Messrs. J. Alexander-Williams and Ivor G. Stephenson on the matching system for preregistration house officer posts in the Birmingham region (9 June, p. 605). It is unfortunate that the authors were unable to consult with students who tonk part in the scheme this year, as they would have found that history is repeating itself: the "unseemly struggle" still persists.

The svstem of patronage by consultants and soliciting by the students has continued in a modified form. Now the consultant promises his job in advance of the official date of receipt of apnlications bv saving, "If you put me first I'll put you first" to the first student who sees him who is acceptable. The basis, presumably, for this is the fear that he will not get the student he wants if he waits for the list of andlications to arrive, and that the matching plan may give him someone he doesn't want.

On the students' side, all is not rosy by any means. It seems that those students who recognize the need to get on in their nrofecsional careers early in their undergraduate course set off on the professional rat race that begins with the preregistration vear bv becoming the first rats to crawl. The fact that they have been promised the inb often becomes known just after the anolications have been made, and thus the other abolicants for that varticular job have wasted one of their limited number (three) of choices.

W/hile I realize that the maiority of consultante plav the game according to the rules, the few who don't do so cause widespread disillusionment among students about the fairness of the scheme. I do not dispute that 